\title{
Representation of Africa online: sourcing practice and frames of reference
}

\begin{abstract}
:
The dominant perspective on the representation of Africa in the western media claims that western media coverage is bias and crisis orientated and the liberal perspective claims that the coverage of Africa is not as negative as is often assumed. However, there is a paucity of literature on the representation of Africa online. This research enquiry is relevant because literature claims that the Internet has the potential to resolve the journalistic predicament of representing other culture through political participation and deliberation. But this requires a re-orientation of the sourcing practice of news organization to embrace sensitivity to and knowledge of African cultures. Moreover, the journalistic predicament can be resolved or not depending on the news gathering approach adopted by the news organization. Literature has identified two approaches, that is, 'gatekeeping' used mainly by dominant traditional media and 'gatewatching' used by alternative media in their quest to counter mainstream ideology.

This study examines the impacts of the 'gatewatching' approach adopted by Africa Have Your Say (AHYS) website on its representation and frames of reference of Africa. It uses on-site observation, in-depth interviews and textual analysis to gather data. The study found that although the sourcing practice at the AHYS is elaborate and complex, the 'gatewatching' approach makes its susceptible to second level agenda setting. Hence, its frame repeats the attributes and tone used by the mainstream traditional media. However, a minority of users did not use repeat this frame in their comments.
\end{abstract}

Keywords: internet, sourcing practice, deliberative democracy, representation, agenda setting. 


\section{Introduction:}

Recently, there are two conflicting perspectives among scholars regarding the representation of Africa in the western media. One dominant/traditional perspective claims that the coverage of African issues is marginalised and contains negative stereotypes. For example, the Voluntary Service Overseas (VSO) "blames the UK media for creating the widespread public perception that people in the developing world are victims, less than human and inferior" (VSO, 2001:3; Brookes, 1995). This perspective attributes such representation to what VSO referred to as the 'Live Aid Legacy' and/or to ideological orientation by arguing that "western media, influenced by their ideological position and/or national interest considerations, will use their hegemonic power systematically to construct negative images (ie violent and conflictual) and media representations of underprivileged others, usually the less-developed countries (Weaver \& Wilhoit, 1984; Leung \& Huang, 2007:676). Therefore, the hegemonic articulation of Africa revolves around poverty, instability, disease, illiteracy and conflict.

However, a liberal perspective challenges the above claim by stating that “...the coverage of Africa, in the UK press at least, is not as negative as is often assumed" (Scott, 2009:548). It contradicts the assumption that the "western media portrays Africa in a disproportionately negative way” (Ebo, 1992:15; Scott, 2009:548) on the grounds that "parts of Africa are places of famine and disease and not to report on such topics would itself be a distortion” (Martin 1994:186; Scott, 2009:548). Moreover, some western journalists claim that "....the problem of access to official sources is severe enough in Africa to kill stories that would otherwise be aired. What do you do as an American journalistic institution... when you have the other side, and the other side wont give it to you?” (Hultman, 1992:232). But surely, the Internet has the potential to resolve the issues at the core of these perspectives by enabling ethnographic communication about Africa, that is, communication from African perspectives.

But presently, the analysis of the representation of Africa in the western media will remain contentious because "as globalization and migration continue to encourage the interaction of different peoples and cultures, so the media portrayal of different parts of the world plays an increasingly important role in either discouraging or promoting respect for other cultures" (Scott, 2009:535). Furthermore, because African countries demand recognition of their milestone achievements in overcoming political and economic challenges by noting the irony of news values that "while many Western households still decry and hold 
visions of horrific newsreels of civilians and children with hacked limbs in Sierra Leone, they have seen little or no reportage of that country's remarkable transition to peace which culminated in one of the continent's most peaceful multi-party elections and transfers of power in October last year (Jere-Malanda, 2008:37). However, the pre-eminence of negativity as a news value negates achievements as salient news in the mainstream media.

Our understanding of the representation of Africa will not be complete without analysing how the potential of the Internet could be harnessed to resolve the journalistic predicament of representing other cultures. But this entails a re-orientation of sourcing practice to include “...effective and sensitive ways of hearing and acknowledging the millions of voices and actions, not to mention silences and inactions, that constitute meaningful human interaction” (Coleman \& Blumler, 2009:168). Furthermore, it will entail, on the part of online journalists, a sensitivity to, firsthand knowledge of African culture and a commitment to democratic principles such as “inclusion (a voice for all), openness (electronic provision of information), security and privacy (a safe place), responsiveness (listening and responding to people) and deliberation (making the most of people's ideas) (Coleman \& Blumler, 2009:149).

There is a growing evidence of the articulation of geopolitical and socio-cultural issues from African perspectives on the Internet. A case example is the repatriation of chimpanzees from USA to Ghana which created much furore in the Ghanaian press but not in western press. The opposition to the repatriation quickly spread to online forum where opposition activists claim that "the chimps had been infected with HIV or cancers, and articulated fears that the animals might bring infections to Ghana” (Schaefer’s 2005:207). This animated online deliberation culminated in a rare evidence of the power of collective voice by forcing the "NDC-dominated Parliament to cancel the chimp relocation programme" (ibid). This outcome undermines the argument of the critics of deliberative democracy “...about the impossibility of vast, physical and temporally dispersed groups of people being able to participate in anything resembling a collective conversation” (Coleman \& Blumler, 2009:19).

The choice of the Africa Have Your Say (AHYS), owned by the BBC World Service (BBCWS), as a case study is based on the claim that it "often provides very positive and balanced coverage of Africa and is faithfully relied upon by persons in Africa” (Martin, 1994:186; Scott, 2009:551). Moreover, the AHYS newsroom is staffed by both black African 
and Caucasian journalists with wide knowledge and experience of Africa. The editor, David Stead, who has a journalistic career spanning 22 African countries claim that "the AHYS is committed to recruit journalists that understand Africa and knowledge of African politics, economics and culture. Therefore, the recruitment process is pretty rigorous in the BBC, regardless of gender and religion. Talent and ability are the key” (interview 2009).

However, the feedback from users indicates that the AHYS has yet to provide positive and balanced coverage of Africa as a user noted: "Do us a favour in 2008 by showing to the world the other side of Africa that is not WARS, AIDS, LESS THAN A DOLLARD A DAY kind of stories. Things are changing in Africa, be part of this good news coming out from Africa now and help reduce the ill feelings about Europe in Africa before it is too late. Let your TV stations create a programme for Africa even if it is once a week, hope that will be good. Understand that if Africa is okay today, much of EU's problems will reduce” (Africa Have Your Say website, 2008) ${ }^{1}$.

Nonetheless, the Internet has the potential to propel African issues to escape "generations of alienation from media production, negative imagery and media mythologizing..." (Alia \& Bull, 2005:103) on the hand; and to enable Africans "to communicate their world views, their cultural products, their commerce, to a global audience” (ibid:104) on the other. Therefore, the AHYS positions itself as a contact zone for deliberation between the moderators, the users and the political establishment. A case example was when the forum instigated an interactive question time between the users and President Attah of Ghana. According to David Stead, “people like a chance to hold leaders to account. So, we allow the users to question leaders. In doing that, we give users access to African leaders and to knowledge they may otherwise not get access to" (interview 2009). As a result, the forum has enhanced its reputation as "unquestionably a medium of predominantly active users; a medium for engaging more widely in, and not just presenting and following, civic dialogue; provides relatively inexpensive public access to large stores of retrievable data...; and facilitates lateral, peer-to-peer and many-to-many interactive exchange” (Coleman \& Blumler, 2009:12).

The overriding aim of any website for Africans is to connect two worlds, that is, the Africans in diaspora and at home in order to achieve “...both culturally specific selfrepresentation and transcultural and global coalition-building” (Alia \& Bull, 2005:106). This rationale differentiates them from the alternative internet which aims to "fill the gaps that its 
reporters believe have been left by the mainstream media” (Atton \& Hamilton, 2008:79) on the one hand; and "operates a practice of open publishing, where all submissions are published" (ibid:80) on the other. Rather, the sourcing practice at the websites for Africans revolves around monitoring or 'gatewatching' of the mainstream news agenda. Moreover, they tend to use mainstream formulas, that is, "story structures (such as the inverted pyramid), sourcing routines that emphasize elite groups in society and news values that privilege events over explanation” (ibid:79). This limits their ability to produce alternative perspectives on Africa and reduces their function to the moderation of negative frames of reference. However, the moderation process at the AHYS is rigorous in line with the house rules but flexible enough to allow users to communicate their meaning.

It is pertinent to differentiate the websites for Africans from citizen media because, unlike the latter, they are not "primarily projects of self education" (Atton \& Hamiltion, 2008:122). However, they share a common orientation in "the provision of opportunities for ordinary people to tell their own stories, and to reconstruct their culture and identity using their own symbols, signs and language” (ibid:122). To illustrate, rape issues in Africa has always been constructed from the perspective of the West, but thanks to the AHYS forum, the Darfur women were able to construct the trauma of rape from the prism of their culture by stating that "before it was a big problem and the father or brothers of the girl would kill the person responsible. But now rape has become common because of the fighting. Previously, the girls would be cast out of society and no young man would marry them. She would be ostracised....Society is changing our ideas and they are supporting these women more by letting them live a normal live...” (Sudan survivors, 2007) ${ }^{2}$. This is an example of how authentic representation can overturn the effects of negative news value.

But the gatewatching role of the AHYS entrenches inter-media agenda setting which happens when "elite media transmit their agenda of important issues to other media" (Coleman et al, 2009:147). At the level of the moderators, issues and the frames of reference in the mainstream are given prominence. And at the level of the users, issues and the frames of reference are recalled and internalised. This is usually the case when users depend on the media as primary resource for constructing “...their own conceptions of what is normal and acceptable” (Berns, 2008:35). Trends in media exposure indicate that "already today, 1.5 billion people use the Internet. In a few years, once the Internet has become genuinely mobile, over 4 billion users and billions more devices and objects will be connected anywhere and anytime”, 
Literature supports the thesis that there is a correlation between media and public agenda setting with increase in media exposure among audiences. For example, it found evidence of second level agenda setting whereby "the attributes and tone that the media use in their descriptions are the attributes and tone foremost in the public mind" (Coleman et al, 2009:148). From this perspective, users can exhibit traits of second level agenda setting in the following ways. First, users who adopt the dominant or hegemonic frame will “...fully shares the text's code and accepts and reproduces the preferred reading (the reading which may not have been the result of any conscious intention on the part of the creator of the text) (Hall, 1980:118). Consequently, a study on violence against women found that "people with no firsthand experience reflect the official reality of abuse" (Berns, 2008:52) by repeating "the reasons, including financial problems, love, guilt, threats, and no social support” (ibid:51).

Second, users who adopt the oppositional (counter-hegemonic) frame will “...understands the preferred reading but does not share it and may bring alternative ways of dealing with it" (Hall, 1980:118). This is because "having experiences beyond the media allowed them to compare and validate, or invalidate, their media based experiences” (Berns, 2008:47). Third, users who adopt personal experience frame “...will draw upon a variety of sources in their interpretation of debate. These sources include their own..., stories from friends, their experience with advocates and other professionals, as well as references from the media" (Berns, 2008:46). Consequently, previous study conclude that "viewers with lifeexperience were more sensitive to televised violence, more subtle and complex in their readings, more concerned about possible effects and more demanding in their expectations of the producers of such content” (Schlesinger, Dobash, Dobash, and Weaver, 1992:165; Berns, 2008:48). And fourth, users who adopt hierarchy of credibility frame will think “...it matters who is talking in determining how much influence the message has on others” (Berns, 2008:44).

But in teasing out these frames, we need to understand the complexity of the sourcing practice at the Africa Have Your Say (AHYS) for evidence of inter-media agenda setting and to analyse the extent to which the moderators and the users adopt the mainstream media's frames of reference. The first task is explored through on-site observation of the AHYS newsroom and an in-depth interview with moderators and editor. The second task is explored through textual analysis of the content of AHYS and in-depth interview with moderators and editor. The scope of study is from 23 November to 23 December, 2008 during which 10 debates and comments were posted. 


\section{Sourcing practice at the Africa Have Your Say website}

The sourcing practice at the websites for African diasporas could be analysed from the concept of 'gatewatching' expounded by Bruns (2005) to contrast the functions of the alternative media from the mainstream media. It means that alternative media "gatewatches the output of both mainstream and other alternative media and re-presents selections from that output in ways that encourage comparison and criticism” (Atton \& Hamilton, 2008:80). Likewise, the Africa Have Your Say (AHYS) monitors issues around the world and represent them from African perspectives. The editor confirms this by stating that "world issues are our story point. For instance, we apply the protest in Iran to the African scene, for example, to Madagascar and Kenya. The Russian debate puts Africa on the world stage. The global economic downturn is now affecting Africa looking at why that was and how remittances have been cut, house prices skyrocketed and private entrepreneurship plummeted through recession. We have made African voices heard in all our programmes” (interview 2009).

My on-site observation took place during the Russia-Africa debate and I was able to observe and participate in the sourcing practice. The monitoring process began by selecting world issues relevant to Africa and the first visit of the Russian President Dimitry Medvedev to a number of African countries was a prominent news agenda. Moreover, it took place a few weeks before the visit of President Barrack Obama to Africa. As usual, the AHYS moderators post a debate on the website to garner opinions from users and select a few comments to read out and a few sources to speak on the Live Radio 'Phone-in' programme at 17hrs. The tone of the debate conforms with the BBC professional news values, that is, "the tone of AHYS is informed, provocative, lively, journalistic and rigorous" (editorial document). For example, there is evidence of provocation in the opening question of the debate, that is, 'Does Africa need Russia?' Then journalistic principle of balance is applied when the moderators posed the follow-up question 'but does Russia need African more than Africa needs Russia?’

Moreover, the construction of the debate is informative by providing establishing statement that "analysts say Russia is keen to increase its sphere of influence on the continent and tap into potential investment opportunities. During the cold war, Russia played a controversial role in shaping the politics and economics of Africa...”4 ${ }^{4}$ The debate then ended with a series of questions to solicit response from the users. The AHYS received a total comment of 253 but 244 were published and nine were rejected. The moderation of 
comments is rigorous without interfering with user's communicative competence. A moderator explains the criteria for moderation to me by stating "we moderate the way you express your view online. We also moderate for offensive comments and relevancy. We also choose comments that help a debate", that is, that enhances the vibrancy of conversation online” (interview 2009). However, the reason for rejecting comments is not because of an infringement of the 'house rules' but because they are not relevant to the debate. Although the moderators monitor the use of about 312 profanities, very few users infringe them. According to a moderator, "users understand the rules. They are astute about how they want to project they views. They understand they are coming on BBC platform” (interview 2009).

The next stage in the sourcing routine happens in the newsroom when the moderators and the editor meet for their morning conference. The sequence of the radio programme is mapped out on the 'story board' including the names of contacts and moderators make contributions to enhance the quality of presentation. Once a decision is made, the callers are then informed and put on standby a few minutes before the broadcast. The editorial document also set out the AHYS' relationship with callers/listeners by stating that "the AHYS puts the callers/listeners first and the programme is driven by their stories and experiences” (editorial document). The whole rationale hinges on the principle that "through taking part in AHYS, callers will have been given the opportunity to tell their story, give their point of view and engage on air with other contributors as part of a pan-African conversation. Listeners should feel better informed, inspired by the stories and empowered by a sense that Africa's voice is being heard and that decision makers are being held to account” (ibid).

This elaborate sourcing practice suggests that the AHYS is geared towards advancing the principles of deliberative democracy. First, the AHYS allow "access to balanced information” (Coleman \& Blumler, 2009:40) by being a 'contact zone' not just for debate but also for retrieving information about global issues through relevant links and blogs. Second, the AHYS is "an open agenda, that is, "the agenda must be open to revision or expansion by the deliberating citizens" (Coleman \& Blumler, 2009:19) by allowing "callers to suggest ideas where these reflect genuine concerns and help the programme in its ambition to be relevant” (editorial document). Third, the AHYS considers “issues expansively” (Coleman \& Blumler, 2009:40) by "providing space for strong debate on significant issues, at times generating news by highlighting under-reported stories and major issues ignored by the media or those in power" (editorial document). Fourth, the AHYS gives users "freedom from manipulation or coercion” (Coleman \& Blumler, 2009:40) by using variety of techniques for 
collating information and contacting sources which include BBC Studios, satellite phones, email, text, facebook, and twitter. Fifth, the AHYS has evolved "a rule based framework for discussion” (Coleman \& Blumler, 2009:40) by "hearing firsthand from those engaged with the stories and issues which affect the continent” (editorial document).

Furthermore, the AHYS seems to meet the sixth principle because it enables "participation by an inclusive sample of citizens..." (Coleman \& Blumler, 2009:40) by encouraging diversity and seeking "to be accessible to the views and opinions of a wide range of contributors which we will mediate impartially, allowing free-flowing debate" (editorial document). Seventh, the AHYS provides "scope for free interaction between participants" (Coleman \& Blumler, 2009:40) by being an "interactive BBC programme connecting Africans wherever they are to discuss what matters to them" (editorial document). And finally, the AHYS recognises “differences between participants" and rejects "status-based prejudice” (Coleman \& Blumler, 2009:40) by selecting a clear and focused subjects for debate which "resonate with listeners around Africa" and aiming for the "highest production standards with clear branding and signposting (editorial document). However, the inclusive sample of users on the forum may not necessarily represent a wide range of perspectives on the issues.

Another relevant dimension of the sourcing practice at the AHYS is that it monitors African websites especially for news that affects British citizens in Africa. For example, the AHYS monitors and reviews the comments on the 'Sudanese thinker blog' via www.sudanesethinker.com by noting that "Sudanese blogs and forums have largely condemned the arrest of British teacher Gillian Gibson for letting her young schoolchildren name a teddy bear Muhammad". Moreover, it noted that "some called the whole issue 'pathetic' and termed Ms Gibson's act 'an honest and innocent mistake'. The media in Sudan and the Middle-East have largely ignored the case”. The AHYS monitors Amjad's blog which carries "comments criticizing the Sudanese authorities" on the same issue. The AHYS also sources information via the facebook and found that a "group formed in www.facebook.com is demanding Gibson's release. The 'Release Gillian Gibbons Now' group carries postings from Sudanese contributors, condemning the arrest and demanding her immediate release”5.

The AHYS monitors the global blogosphere on the Gibson case and notes that "a brief survey by BBC Monitoring on 29 November 2007 indicated that the story was not yet featuring prominently in the global blogosphere. For example, a search on the Technorati 
website at 0945 GMT produced fewer than 300 hits, mostly from US and UK bloggers. However, many of these postings were merely links to factual reports on mainstream news websites such as International Herald Tribune. The affair has been widely reported in the UK press, and the London-based pan-Arab press have carried factual reports. However, media in the Middle East appear to be playing down the story, which has so far been overshadowed by comment on the Annapolis meeting”,

The AHYS monitors other African blogs on a wide range of issues. For instance, in the aftermath of the political crisis in Kenya it monitored www.mashada.com - "a prominent online forum frequented by Kenyans in the diaspora". According to its moderator, "this forum exists to facilitate civil discussions and debates. Condescending, rude, and annoying remarks and insults are awarded with temporary and permanent bans". AHYS began the review with an establishing statement that "Kenyan's political crisis sparked by the disputed presidential election continues to dominate debate on the country's blogs and online forums. Orange Democratic Movement (ODM) leader Raila Odinga says he was robbed of victory in December by Mwai Kibaki, who was declared the winner”. However, the AHYS found that “while some bloggers condemned attacks on 'unarmed, innocent and defenceless' Kikuyus, others supported the displacement of Kikuyus who 'grabbed peoples land'”. The AHYS also found on a rival blog, that is, kenya.rcbowen.com a comment by Justice that "the ethnic Kalenjin community should immediately occupy their ancestral lands which [late] President Jomo Kenyatta took from them and dished out to his Kikuyu”. Finally, the AHYS balanced the review of the blog with an overview of newspapers in Kenya "that The Standard and Daily Nation newspapers have reported that leaflets were circulating in Central Province - the Kikuyu heartland - warning members of other ethnic communities to leave. The reports said that close to 1,200 people had left their homes in fear and were camping at police stations, and that at least four of them were suffering from bad knife wounds, after they were attacked"?.

Of course, there are other websites for Africans that the AHYS do not monitor or review. Most of these can be categorised broadly into "“meta and comment' sites; and 'share and discussion' sites” - two of the 'four types of online journalism' identified by Deuze (2003). For example, the www.nigeriavillagesquare.com falls under the former while the AHYS is a hybrid of both. However, the 'Ghana Forum' and 'Say It Loud' analysed in Schaefer's (2006) study could be classified as 'share and discussion' sites because they are contact zones "where members of the Ghanaian diasporic opposition community meet and 
debate with members of the domestic political community and interested others" (Schaefer, 2006:203). The www.ghanaweb.com and http://saharareporters.com/ are hybrid of news, comment and index site. For example, it gives priority to top stories, crime, politics, diaspora, regional, health and religion on the top of the index page. This is followed by sports, business, entertainment, country, opinion and members. The index page ends with A-Z resource on a wide range of subjects. The Sahara Reporters' site which also has a video link describes itself as "an online community of international reporters and social advocates dedicated to bringing you commentaries, features, news reports from a Nigerian-African perspective”.

There is no doubt that the Africans are appropriating the Internet to represent Africa from African perspectives and to project their cultural and African identities. However, the low penetration of Internet estimated at 6.7 percent compared to 24.7 percent of the world average8 indicates the depth of the digital divide which puts the Africans at home at a disadvantaged compared to the counterpart in diaspora. Moreover, there is evidence of digital divide between countries. For instance, the continent's top ten internet countries are Egypt at 12.6 million people, Nigeria at $11 \mathrm{~m}$, Morocco at $10.3 \mathrm{~m}$, South Africa at $4.6 \mathrm{~m}$, Sudan at $3.8 \mathrm{~m}$, Algeria at $3.5 \mathrm{~m}$, Kenya at $3.4 \mathrm{~m}$, Tunisia at $2.8 \mathrm{~m}$, Uganda at 2.5 and Zimbabwe at $1.4 \mathrm{~m}^{9}$. The Internet penetration in the remaining 43 African countries is not statistically significant to warrant any mention. The implication is that digital divide will undermine efforts by websites for Africans to mount any significant challenge against the negative representation of Africa and their ability to rival the global media in terms of reach, capital and network of contacts.

Regarding reach, the AHYS is an integral part of a conglomeration of websites owned by the BBC World Service to extend its programming “...in 37 languages in real audio on the Internet...” ${ }^{\prime 10}$. Their remit is to '...connect and engage audiences by facilitating an informed and intelligent dialogues - a global conversation - which transcends international borders and cultural divides, and...give audiences opportunities to create, publish and share their own views and stories”"11. Regarding capital, the AHYS is funded from the extra grant of $£ 64$ million the World Service received over three years ${ }^{12}$ in 2001 . However, the websites for Africans are constrained by capital because they are mostly authored by enthusiasts and former journalists. The hope of generating income from the net is also remote because their hierarchy of credibility is low in the estimation of advertisers. Regarding network of contacts, the websites for Africans cannot compete either. Whereas, the editor of AHYS takes pride in the statement that the "network of reporters and our contacts" is the AHYS' unique selling 
point. Furthermore, "we have 200 African stringers across Africa. Hence, our ability to report Africa in a pan-African way is second to none. For instance, Capitol Radio in Kenya may be good on Kenyan issues but listeners cannot use it to find out what is going on in Nigeria. So, if you want to know where your country 'fits in' in African terms, then AHYS provides that” (interview 2009).

However, it is fair to note that both the AHYS and websites for Africans share a common editorial practice by being a platform for breaking news, eyewitness account and commentary. For example, Sahara Reporters broke the news of the political assassination of Otunba Dipo Dina, a governorship candidate of the Action Congress (AC) in the 2007 elections in Ogun State, and warned that "the murder of Dipo Dina has once again raised the political temperature of the Southwest in particular; and Nigeria in general as we move towards 2011 elections”"13. This news agenda contrast with that of the AHYS which focused on the debate titled 'How can Africa help Haiti' ${ }^{14}$. Nonetheless, both websites cater for the information needs of users and serve as ‘contact zone’ for global conversation.

\section{An analysis of frame of reference used by users}

User empowerment and interactivity are at the core of the appeal of the AHYS among Africans at home and in diaspora. But let us begin by analysing the data about the profile of the users and their location. According to the editor, "the users of AHYS are literate and they cut across a wide age group, urban, middle class people and are engaged with global issues” (interview 2009). For Africans at home, this means the forum is for the cosmopolitan user who can afford to buy computers and subscribe to internet service provider and/or access from office or the Internet café. However, the penetration of AHYS to rural Africa is a goal that the BBC World Service is pursing and the moderators think it is possible to achieve it in the near future because of the penetration of mobile phone in Africa and its use for internet connection. But for Africans in diasporas, the profile means that the forum is for the educated user who is interested in African and global affairs and eager to make a contribution. The study examined the ten debates in Table 1 for location of users.

\section{Chart 1: AHYS User Location}


Chart 1 above indicates that the users are mostly located in USA, UK and Canada. This is not surprising because Africans in diaspora have better access to computer and internet facilities. Unlike their counterpart who must overcome the challenges of incessant power failure, high tariff internet connection, unaffordable computer prices, scarcity of internet café, internet/media illiteracy etc. These and other socio-economic and political challenges exacerbate the digital divide between the Africans at home and in diaspora. However, users in Nigeria and Ghana have a strong showing and this may be a reflection of colonial heritage which continue to manifest itself through language, education, media and other cultural industries. This colonial heritage may explain why the "forum has no single user from Burundi and occasionally get some from Rwanda” (interview 2009). The data also reveals that a significant number of users did not indicate their location. This is an optional preference and some users decide to exercise the right to anonymity. The category 'others' represent countries where the data found less than twenty users.

Chart 2: The frame of reference in users’ comments

As mentioned earlier, the frame of reference used by moderators can engender second level agenda setting among users. This is evident through the repetition of attributes and tone used by moderators. Chart 2 above confirms that majority of users ( 57 percent) accept the frame/tone of the debates and are most likely to use the hierarchy of credibility to enhance their argument. For example, an unedited comment by a user in response to the debate titled 'Is violence against women inevitable?' states:

"In Africa or anywhere else, this bit of news 'Women and girls in Cambodia are facing an increasing risk of rape and sexual assault says a government report. Doesn't give much hope or...does it? Men are animals though more in some parts of the world than others. Education will go a long way to solve the problem but its not a final solution as long as minds are sick and laws in some countries allow men to get away with it” - Artur de Freitas, Johannesburg, South Africa.

It is noteworthy how the user cited government report to justify the claim that it is widespread and not limited to a particular part of the world. The user also vent out anger on the government for not tightening the law. 
However, a significant number of users (43 percent) rejected the frame/tone and are most likely to cite sources outside of the media to enhance their argument. For example, an unedited comment by a user on a debate titled 'Is Ghana’s star dimming?’ notes:

"how can our star continue to shine if we continue to obey our bosses, IMF, WORLD BANK, and the West, embarking on programmes like the ERPs, SAPs. Privatisations, etc have left us more poor, look at what Dr Kwame Nkrumah our first president did, no government have been able to make an impact on our development process than him. Our star is black for that matter I can say that the 'black' star problems needs 'black' solutions and not 'white' solutions. This is the only way our star can shine, thanks” - Emmanuel Wullingdool, Accra.

Moreover, such users use a combination of sources to justify their opinion, that is, statistics, reference to other media outlets and hierarch of credibility. For example, a user countered the hegemonic attribution and tone of the debate titled 'Is violence against women inevitable?' by stating:

“it's not just Africa. from a BBC article: one third of women in Wales suffer from some sort of violence, three members of the Welsh assembly have disclosed that they have been raped, a NUS survey of Welsh students found that 64\% knew women whose partners had hit them, and $41 \%$ knew women who had been pressured into sex, a third believed a woman was responsible or being raped if she was drunk or flirtatious, and a quarter thought she was to blame if she walked alone in a deserted area” - Chris X, Edinburgh.

From the above, the data reveals evidence of second level agenda setting as majority of users repeat the frame and tone used by moderators. That implies that the issues are 'unobtrusive' for the first category of users, that is, "those with which people have little to no personal experience, are the ones most likely to become important to people if they are high on the media's agenda” (Coleman, 2009:153). Therefore, they have a high propensity to internalise moderators' frame. But the issues are 'obtrusive' for the second category of users, that is, they have a high propensity to use alternative frames or to draw from "direct or personal experience with an issue" (ibid:153). Hence, they have a propensity to use oppositional (counter-hegemonic) frame and tone in their comments.

\section{An analysis of the frame of reference used by moderators}


As mentioned earlier, monitoring or 'gatewatching' is an integral part of the sourcing practice at the AHYS. As a result, the moderators are predisposed to reflect the frames of reference in the mainstream or alternative media. The analysis of the ten debates in Table 1 will give us an insight into the extent of the inter-media agenda setting.

Table 1: $\quad$ Published and Rejected Comments.

Table 1 reveals a grand total of 1496 comments out of which 85.49 percent was published and 6.28 percent was rejected. This high publication rate suggests that the forum is user friendly and the moderators are committed to diversity of opinions and deliberation among users. The textual analysis reveals that three of the debates embed economic frame, two embed socio-cultural frame, one embeds legal/socio-cultural frame, one embeds health frame, two embed political frame and one embeds legal/ethical frame. Interestingly, the economic frame is most likely to harbour mixed and negative tones, the socio-cultural frame harbours mixed tone, the legal/socio-cultural harbours negative tone, the health frame harbours neutral tone, the political frame harbours mixed and negative tones, and the legal/ethical harbours negative tone. To illustrate, the debate titled 'Is Ghana's star dimming?' is an example of a political frame but with mixed tone. It harbours hegemonic articulation of democratic institution in Ghana by insinuating instability, vote rigging and lack of transparency. This provoked a high response rate with a total of 564 comments. Below is an unedited comment by a user in response to the hegemonic construction of African political reality on the forum:

'I think most of the international media left disappointed here, because there was not much story to be carried out right after the polls, my reasons are simply, there was not no news on rigged, beating or any negative story to report. Supposedly there was this negative stuff, you will see how the big media will trumpet them all over the world and paint African black’ - Yaw Tawiah, Adenta

Moreover, moderators used hierarchy of credibility to underpin the political frame. For example, it cited the announcement by Ghana's Electoral Commission that the presidential election will be decided in a second round vote. This was reinforced by statistics of percentage of the vote won which was below the 50 percent needed to score an outright win. Such use of hierarchy of credibility is a common journalistic practice to demonstrate impartiality and objectivity. However, there was no evidence that the moderators balanced 
the views of official sources with eyewitness accounts. Hence, the moderators need to do more to recognise the latter as reliable sources.

The debate titled 'Is violence against women inevitable?' is an example of legal/socio-cultural frame with negative tone. The moderators used the hierarchy of credibility by quoting statistics from the World Health Organization (WHO) regarding the spate of the abuse across developing countries. For example, " $50 \%$ of women in Ethiopia, Tanzania, Bangladesh and Peru reported they were subjected to physical or sexual violence by their partners, with figures reaching staggering $71 \%$ in rural Ethiopia. In South Africa, the government says more than 55,000 rape cases are reported every year - the highest on the continent”. However, it did not contrast these incidents with statistics from developed countries. Hence, it has a tendency to cause moral panic and reinforce negative stereotypes of Africa among users.

The debate titled 'Does HIV/AIDS still scare you?' is an example of health frame but with neutral tone. The moderators did not reinforce the hegemonic articulation of infectious Africa that is common in mainstream media. Therefore, the debate opens thus: "when Aids first began to spread in the early 1980s it brought fear and confusion with many seeing it as a death sentence". This tone will motivate users to draw upon their personal experience. The moderator went further to question why expectations about vaccine being produced have not been met, two decades after the claim was made. This use of hierarchy of credibility put the blame squarely at the door of experts and pharmaceutical companies. The debate was articulated from the perspective of the victim.

Overall, the data reveals that the moderators gave prominence to economic, political and socio-cultural frames but with a fixation on mixed and negative tones. Consequently, some users with limited exposure to other sources of information may continue to hold a stereotypical view of Africa. This analysis should be instructive for the moderators because it illuminates how the construction of the debate could engender second level agenda setting among users, that is, "the attributes and the tone that the media use in their descriptions are the attributes and tone foremost in the public mind” (Coleman et al, 2009:149).

\section{Conclusion:}


The study reveals that the sourcing practice at the AHYS is underpinned by monitoring or 'gatewatching'. This is further confirmed by the editor in describing the souring routine that "generally, topics for debate are generated from what is on the news. It is then framed for the website and later presented on AHYS radio. The moderator also writes a feature on the breaking news for the website. This process ensures that the debate and conversation last for a week" (interview 2009). The implication is that the AHYS is susceptible to inter-media agenda setting with a tendency to repeat the frame of reference in the mainstream media. Therefore, the forum has been found to perpetuation some negative stereotypes in representing Africa. The forum needs to device a team driven and flexible souring routine in order to realise the potential of the Internet to foster better understanding of other culture. Presently, such flexibility is limited to responding to mainstream news agenda as noted by the editor that "the team is flexible enough to change the topic if there is a breaking news" (ibid). What is needed is an overhaul of the souring practice to elicit the best of technical skills, professional values, sensitivity to and knowledge of Africa.

Such sourcing practice will make issues more 'obtrusive' to users and make the forum a reference point in their analysis of messages in television which came out top in order of preference in a survey by the Pew Center for the People \& the Press in 2008. The survey found that "eight out of ten Americans get the news every day, but the sources of the news are changing..., 57 percent of those seeking news watched television, 35 percent listened on the radio, 34 percent read newspapers, and 29 percent went online” (Foreman, 2010:11-12). The future trend is that preference for online news will continue to rise. Therefore, representation of Africa online needs to be accurate, devoid of negative stereotypes, informed by knowledge of Africa and African cultural practices. 


\section{Notes}

1 Africa

Have Your

Say

(AHYS)

Website

http://news.bbc.co.uk/2/hi/talking_point/africa_have_your_say/default.stm

Accessed April 6, 2009.

2 Sudan

survivors

answer

your

questions

http://newsvote.bbc.co.uk/mpapps/pagetools/print/news.bbc.co.uk/1/hi/world/afri $\underline{\mathrm{ca} / 7}$ accessed Oct 29, 2009.

3 http://ec.europa.eu/information_society/activities/foi/index_en.htm accessed November 20, 2009).

4 Africa Have Your Say (AHYS) Website http://news.bbc.co.uk/2/hi/talking_point/africa_have_your_say/default.stm

Accessed June 9, 2009.

5 Bloggers condemn Sudan for arrest http://news.bbc.co.uk/go/pr/fr//1/hi/world/africa/7119391.stm accessed November 12, 2009.

6 Battle of the blogs in Kenya http://news.bbc.co.uk/go/pr/fr//2/hi/africa/7189291.stm accessed November 12, 2009.

7 Ibid

8 Sahara Reporters http://saharareporters.com/ accessed 26 January, 2010.

9 www.internetworldstats.com accessed November 12, 2009.

10 www.bbc.co.uk/worldservice/us/anual_review/2006/ accessed September 25, 2009.

11 ibid

12 www.fco.gov.uk/en/newsroom/latest-news/?view=Speech\&id=2148677 accessed November 12, 2008.

13 Sahara Reporters http://www.saharareporters.com/ accessed 26 January, 2010. 
14 http://newsforums.bbc.co.uk/nol/thread.jspa?forumID=7421\&edition=1\&ttl=201

$\underline{00126153642}$ accessed 26 January, 2010.

15 www.fco.gov.uk/en/newsroom/latest-news/?view=PressR\&id=2021148 accessed November 12, 2009.

\section{References}

Alia, Valerie \& Bull, Simone (2005) Media and Ethnic Minority. Edinburgh. Edinburgh University Press.

Atton, Chris \& Hamilton, James F. (2008) Alternative Journalism. Los Angeles. Sage.

Bakker, Piet \& Sadaba, Charo (2008) 'The impact of the internet on users' pp. 86 - 101 in Lucy Kung, Robert G. Picard \& Ruth Towse, The Internet and the Mass Media. Los Angeles: Sage.

Baroness Scotland (2002) Baroness Scotland Publicises BBC World Service Internet Services to UK Minority Ethnic Communities

$\underline{\text { www.fco.gov/en/newsroom/latest-news/?view=PressR\&id=2021148 }}$ Accessed November, 12, 2008.

Berns, Nancy (2008) Framing the victim. Domestic violence media and social problems. London: Aldine Transaction.

Brookes, H. (1995) 'Suit, Tie and a Touch of Juju - The ideological construction of Africa: A discourse analysis of news on Africa in the British Press', Discourse and Society 6 (4): 46194.

Bruns, Axel (2005) Gatewatching: Collaborative online news production. New York: Peter Lang.

Coleman, Stephen \& Blumler, Jay G. (2009) The Internet and Democratic Citizenship. Theory, Practice and Policy. Cambridge: Cambridge University Press. 
Coleman, Renita, McCombs, Maxwell, Shaw, Donald \& Weaver, David (2009) 'Agenda Setting' in Karin Wahl-Jorgensen \& Thomas Hanitzsch (eds) The Handbook of Journalism Studies, pp. 147 - 160. New York: Routledge

Deuze, Mark (2003) 'The Internet and its journalisms: considering the consequences of different types of newsmedia online', New Media and Society 5 (2), June: 203 - 30.

Ebo, B. (1992) 'American Media and African Culture’, pp. 15 - 25 in B. Hawk (ed.) Africa’s Media Image. New York: Praeger.

Foreman, Gene (2010) The Ethical Journalist. West Sussex: Wiley-Blackwell.

Hall, Stuart (1980) Encoding/decoding in S. Hall, D. Hobson, A. Lowe and P. Willis (eds) Culture, media language. Hutchinson, London.

Hultman, Tami (1992) 'Dateline Africa: Journalists Assess Africa Coverage' in B. Hawk (ed.) (1992) Africa’s media image. London: Praeger.

Jere-Malanda, Regina (2008) And now...Positive Africa. New African magazine, June, pp. 36 -40 .

Leung, Christine C.M. \& Huang, Yu (2007) The paradox of journalistic representation of the other. Journalism, Vol 8(6): 675 - 697.

Martin, R. (1994) 'The Mass Media: Image and Reality - Africa’s Media Image by Beverly G. Hawk', Journal of Modern African Studies, 32 (1): 183 - 9.

Schaefer, John Philip (2006) 'Discussion lists and public policy on iGhana: Chimps and feral activist' in Kyra Landzelius, Native on the Net. Indigenous and Diasporic Peoples in the Virtual Age, pp. 202 - 219. Routledge: London \& New York,.

Schlesinger, Philip, R. Emerson Dobash, Russell P. Dobash \& C. Kay Weaver (1992) Women viewing violence. London: British Film Institute.

Scott, Martin (2009) 'Marginalized, negative or trivial? Coverage of Africa in the UK press', Media, Culture \& Society, Vol 31(4): 533 - 557.

VSO (2001) Live Aid Legacy. London:VSO 
Weaver, D.H. \& Wilhoit, C.C. (1984) 'Foreign news in the western agencies', in R.L. Stevenson \& D.L. Shaw (eds) Foreign News and the New World Information Order, pp. 153 - 85. Ames, IA: The Iowa State University Press.

Zhou Xiang, Chan, Yeun-Ying and Peng, Zhen-Mei (2008) Deliberativeness of online political discussion. A content analysis of the Guangzhou Daily website. Journalism Studies, Vol. 9, No. 5, pp. 759 - 770. 